\title{
Weaning age affects growth, feed intake, gastrointestinal development, and behavior in Holstein calves fed an elevated plane of nutrition during the preweaning stage
}

\author{
E. Eckert, ${ }^{*}$ H. E. Brown, ${ }^{*}$ K. E. Leslie, $†$ T. J. DeVries, ${ }^{*}$ and M. A. Steele $\ddagger \S^{1}$ \\ *Department of Animal and Poultry Science, and \\ †Department of Population Medicine, University of Guelph, 50 Stone Road East, Guelph, ON, N1G 2W1, Canada \\ ¥Nutreco Canada, 150 Research Lane, Guelph, ON, N1G 4T2, Canada \\ §Department of Agricultural, Food and Nutritional Science, University of Alberta, Edmonton, T6G 2P5, Canada
}

\section{ABSTRACT}

Recent research has revealed potential advantages of feeding an elevated plane of nutrition to calves during the preweaning period. However, calves fed more nutrients preweaning may be more susceptible to depressed growth and weaning stress during the transition from liquid to solid feed. The objective of this study was to investigate the relationship between the age of weaning and feed intake, and its influence on growth, gastrointestinal development, and behavioral indicators in dairy calves fed an elevated plane of nutrition during the preweaning period. To meet this objective, 20 female Holstein calves were randomly assigned at birth to be weaned at 6 or 8 wk. Milk replacer (mixed at $150 \mathrm{~g} / \mathrm{L}$ ) was offered at $1.2 \mathrm{~kg} /$ calf per day in 2 meals until a 1-wk step-down, when meals were reduced by $50 \% 1 \mathrm{wk}$ before weaning. Daily starter, chopped oat straw, water intake, and weekly body weights were measured until d 70 of life. To assess digestive tract development, rumen fluid, fecal, and blood samples were taken before and after weaning (d 35, 49, and 63) and analyzed for ruminal short-chain fatty acids, blood $\beta$-hydroxybutyrate, and fecal starch, respectively. Behavioral indicators of weaning stress, including vocalizing and non-nutritive oral behavior, were measured by visual observation for $1 \mathrm{~h}, 3$ times per week, before the second feeding of the day during the period from 2 wk before weaning to 2 wk after weaning. The calves weaned at 8 wk compared with 6 wk had higher average daily gain for the week preweaning $(0.79 \pm 0.09$ vs. $0.34 \pm 0.10 \mathrm{~kg} / \mathrm{d})$ and postweaning $(1.05 \pm 0.09$ vs. $0.35 \pm 0.11 \mathrm{~kg} / \mathrm{d})$, and were heavier at $\mathrm{d} 70(99.9 \pm 1.81$ vs. $91.0 \pm 2.26 \mathrm{~kg})$. From 5 to 8 wk of age, starter and water intakes were lower in calves weaned at $8 \mathrm{wk}$ of age. However, overall starter intake did not differ during the last week of the experiment. Furthermore, calves weaned at $8 \mathrm{wk}$

Received November 4, 2014.

Accepted May 10, 2015.

${ }^{1}$ Corresponding author: masteele@ualberta.ca compared with 6 wk had higher starter intake for 1 wk preweaning $(1.36 \pm 0.13$ vs. $0.40 \pm 0.08 \mathrm{~kg} / \mathrm{d})$ and postweaning $(2.51 \pm 0.20$ vs. $1.16 \pm 0.15 \mathrm{~kg} / \mathrm{d})$. In both treatments, weaning increased ruminal short-chain fatty acids, blood $\beta$-hydroxybutyrate, and fecal starch, yet the differences between the week before and after weaning were greater for calves weaned at 6 wk compared with those weaned at 8 wk. Treatment $\times$ week relative to weaning interactions indicated that several behaviors varied between early- and later-weaned calves during the week before weaning; calves weaned at $6 \mathrm{wk}$ tended to exhibit $75 \%$ more non-nutritive oral behavior and spent $55 \%$ less time ruminating, and $36 \%$ less time lying compared with calves weaned at $8 \mathrm{wk}$. Under the conditions of this study, the results suggest that calves fed an elevated plane of nutrition preweaning have higher starter intakes and average daily gain during the weaning period when weaning is extended from 6 to 8 wk of age.

Key words: calves, weaning, age, development, behavior

\section{INTRODUCTION}

Dairy calves are born as pseudo-monogastrics, without a functioning rumen, and they initially rely on milk to ensure they receive enough energy for maintenance and growth (Baldwin et al., 2004). When calves are left to nurse from their dam or offered milk ad libitum, they often drink up to $12 \mathrm{~L}$ of milk per day (de Passillé et al., 2008; de Passillé and Rushen, 2012), in 8 to 12 meals a day (Reinhardt and Reinhardt, 1981). The weaning process occurs gradually over many weeks when calves are left to nurse from their dams and is completed at approximately 10 mo of age (Reinhardt and Reinhardt, 1981). In commercial dairy production systems, feeding milk is more costly than feeding solid feed. Therefore, transitioning calves from milk to solid feed as early as possible has traditionally been perceived as a way to decrease feed costs. Early weaning methods were developed based on encouraging solid feed intake by restrict- 
ing milk feeding levels to approximately $10 \%$ of birth BW, which is much less than half of ad libitum consumption. Because consumption of solid feed initiates rumen papillae development, the sooner an adequate amount of starter is consumed, the sooner weaning can successfully occur (Kertz and Loften, 2013). However, calves fed restricted levels of milk typically display behavioral signs of stress and have poor growth rates $(<0.5 \mathrm{~kg} / \mathrm{d}$; Noller et al., 1962; Winter, 1985; Kertz et al., 1979), as well as indications of hunger and significant welfare issues (Khan et al., 2011).

Over the past decade, there has been a movement toward offering more milk-based nutrients in early life to achieve improved health, growth rates, feed efficiency, and lifetime milk production (Soberon et al., 2012). In spite of the benefits to performance and health, feeding calves higher planes of nutrition preweaning is still not advocated in all circumstances. One reason for the lack of implementation is that feeding calves larger amounts of milk delays solid feed intake, which may compromise rumen development before and during weaning, as well as affect postweaning growth (Appleby et al., 2001; Jasper and Weary, 2002). Supporting this concept, Sweeney et al. (2010) found that calves fed large amounts of milk displayed decreased postweaning intake and weight loss during an abrupt weaning scheme at $40 \mathrm{~d}$ of age. The gastrointestinal tract might be too premature in its development to support solid feed intake and growth during weaning (Baldwin et al., 2004).

Little information exists on the effects of weaning age on solid feed intake, growth, digestive tract development, and behavior for higher planes of nutrition during the preweaning period. It can be expected that the transition becomes more challenging at higher planes of nutrition due to less solid feed intake; however, further research is required to determine the optimal weaning age when calves are fed higher quantities of milk under diverse feeding schemes and systems. The objective of this experiment was to characterize the effect of weaning age on dietary intake, growth, digestive tract development, and feeding behavior of the dairy calf. We hypothesized that calves fed an elevated plane of nutrition $(1.2 \mathrm{~kg}$ of milk replacer $/ \mathrm{d})$ weaned at 8 versus 6 wk would have higher growth rates, more advanced gastrointestinal development, and decreased behavioral signs of hunger during the weaning period.

\section{MATERIALS AND METHODS}

\section{Animals and Housing}

The use of 20 Holstein calves for this study was approved by Nutreco Canada's Agresearch's (Guelph,
ON, Canada) Animal Care Committee, in compliance with the guidelines set by the Canadian Council on Animal Care (CCAC, 2009). Calves were enrolled in the study at birth, after being transferred from a maternity pen to a naturally ventilated calf nursery barn at Eckerlea Acres Dairy Farm (Seaforth, ON, Canada). In the nursery, calves were placed in individual pens (1.83 m wide $\times 2.74 \mathrm{~m}$ long; $\left.5.01 \mathrm{~m}^{2}\right)$ for the remainder of the study. Pens were bedded with wood shavings, and soiled shavings were removed daily and replaced as needed. The front of each pen had 4 openings mounted to the gates to facilitate the holding of the feeding pails (top diameter $=12 \mathrm{~cm}$, bottom diameter $=8 \mathrm{~cm}$, height $=22 \mathrm{~cm}$, capacity $=7 \mathrm{~L}$ ). The first opening held a pail containing ad libitum calf starter. The second opening held a pail containing ad libitum chopped oat straw $(3 \mathrm{~cm})$. The third and fourth openings held pails containing ad libitum water; 2 pails were used to ensure calves always had access to water if drinking more than 1 pail between visits.

Within $4 \mathrm{~h}$ of birth, calves were weighed and offered $4 \mathrm{~L}$ of their dam's colostrum by nipple bottle (Super Calf Nipple; Merrick's, Middleton, WI). If they drank $3 \mathrm{~L}$ or more, it was deemed sufficient and the volume was recorded. Colostrum quality was measured with a Brix refractometer (Equine Colostrum Refractometer; Animal Reproductive Systems, Chino, CA) and was discarded if it measured less than 22 on the Brix scale (Bielmann et al., 2010). If the dam produced colostrum of insufficient quality or quantity, frozen colostrum of sufficient quality was thawed and fed to the calf. On the first day of life, each calf was given a 1-mL subcutaneous injection of selenium and vitamin E supplement (Dystosel; Pfizer Animal Health, Kirkland, QC, Canada) and a 1-mL subcutaneous injection of tildipirosin solution (Zuprevo; Merck Animal Health, Summit, NJ) as a preventative measure to reduce incidence of illness (Stanton et al., 2013). At the first milk feeding after colostrum and for the next $6 \mathrm{~d}$, each calf was given 8 $\mathrm{mL}$ of halofuginone lactate by oral applicator (Halocur; Merck Animal Health, Summit, NJ) immediately following the morning feeding to reduce morbidity from cryptosporidiosis (Trotz-Williams et al., 2011).

\section{Milk, Starter, Chopped Straw, and Water Feeding}

After the initial colostrum feeding, all calves were fed a milk replacer solution (MR) twice daily (0730 and $1630 \mathrm{~h}$ ) by nipple bottle (Super Calf Nipple). As calves became stronger, they were transitioned at $7 \pm 3$ d to a gate-mounted artificial teat (Peach Teats; Skellerup Industries Ltd., Woolston, New Zealand), through which they were fed until weaning. The artificial teat feeding setup consisted of the teat mounted at the front 
of the pen, attached to a tube fitted with a one-way valve, running into an 8 -L bucket placed outside the pen. All buckets, lines, and teats were cleaned daily in the morning after feeding.

Shur-Gain Optivia High Performance (26\% CP, $16 \%$ fat; $\mathrm{ME}=4.58 \mathrm{Mcal} / \mathrm{kg}$ ) Milk Replacer (Nutreco Canada Inc., Guelph, ON, Canada), mixed at a rate of $150 \mathrm{~g}$ to $1 \mathrm{~L}$ of $40^{\circ} \mathrm{C}$ water was used for the study. The MR was prepared at each feeding in sufficient volume to feed all calves. From birth to d 70, pelleted calf starter $(22 \% \mathrm{CP} ; \mathrm{ME}=2.63 \mathrm{Mcal} / \mathrm{kg})$ was offered ad libitum. It was delivered daily at $0900 \mathrm{~h}$ and orts were weighed and discarded. From birth to d 70, oat straw $(8 \% \mathrm{CP} ; \mathrm{ME}=1.55 \mathrm{Mcal} / \mathrm{kg})$ chopped to a length of $3 \mathrm{~cm}$ was offered ad libitum; it was delivered daily at $0900 \mathrm{~h}$ and orts were weighed and discarded. From birth to d 70, water was delivered daily at $0900 \mathrm{~h}$ and offered ad libitum; orts were measured volumetrically and discarded. Additional starter, straw, and water were added throughout the day, and recorded, if necessary to ensure continuous availability.

\section{Experimental Design and Intake and Growth Measurements}

At birth, each calf was randomly assigned to either the 6 -wk $(\mathbf{6 W W})$ or 8 -wk $(\mathbf{8 W W})$ weaning protocol. All calves allocated to the study were collected over a period of $1 \mathrm{mo}$. Calves were offered $6 \mathrm{~L}$ from $\mathrm{d} 1$ to $3,7 \mathrm{~L}$ from $\mathrm{d} 4$ to 6 , and $8 \mathrm{~L}$ from $\mathrm{d} 7$ until their respected time of step-down weaning (Figure 1A). The $6 \mathrm{WW}$ group was stepped down to $4 \mathrm{~L} / \mathrm{d}$ on $\mathrm{d} 36$ and weaned on $\mathrm{d} 43$. The $8 \mathrm{WW}$ group was stepped down to $4 \mathrm{~L} / \mathrm{d}$ on d 50 and weaned on d 57 . Intakes of starter, straw, and water were recorded daily at $0900 \mathrm{~h}$. Intake of MR was recorded twice daily at each feeding. Calves were weighed at the same time of day $(1100 \mathrm{~h})$ weekly ( $\pm 1 \mathrm{~d})$ starting at birth until d 70 . Additional weight measurements were taken at 90 and $150 \mathrm{~d}$ to assess the long-term effect of weaning age treatment on growth.

\section{Rumen Fluid, Fecal Matter, and Blood Collection}

To characterize digestive tract development before and after weaning, rumen fluid was collected on d 35, 49 , and $63( \pm 1 \mathrm{~d})$ using a Geishauser probe designed specifically for calves, as described by Benschop and Cant (2009), at 1100 h. Ruminal pH was immediately determined using a handheld $\mathrm{pH}$ meter that was calibrated before every reading ( $\mathrm{pH} 310$, Oakton Instruments, Vernon Hills, IL). Rumen fluid samples were collected and preserved for short-chain fatty acids (SCFA) analysis by mixing $5 \mathrm{~mL}$ of rumen fluid with $1 \mathrm{~mL}$ of $0.06 \mathrm{M} \mathrm{HCl}$. All aliquots were immediately frozen at $-20^{\circ} \mathrm{C}$. In between each use, the rumen collecting apparatus was cleaned with water and ethanol to prevent contamination of rumen fluid samples from calf to calf. The rumen fluid was analyzed for SCFA using gas chromatography (Mutsvangwa et al., 2002). To assess total-tract starch digestibility, fecal samples (50 g) were collected on wk 5, 7, and 9, frozen immediately, and stored at $-20^{\circ} \mathrm{C}$ until analysis. In brief, calves were rectally finger-stimulated with a sterile-gloved hand to facilitate the collection of a fecal sample. Fecal samples were dried at $60^{\circ} \mathrm{C}$ for $48 \mathrm{~h}$ before grinding to a $1.0-\mathrm{mm}$
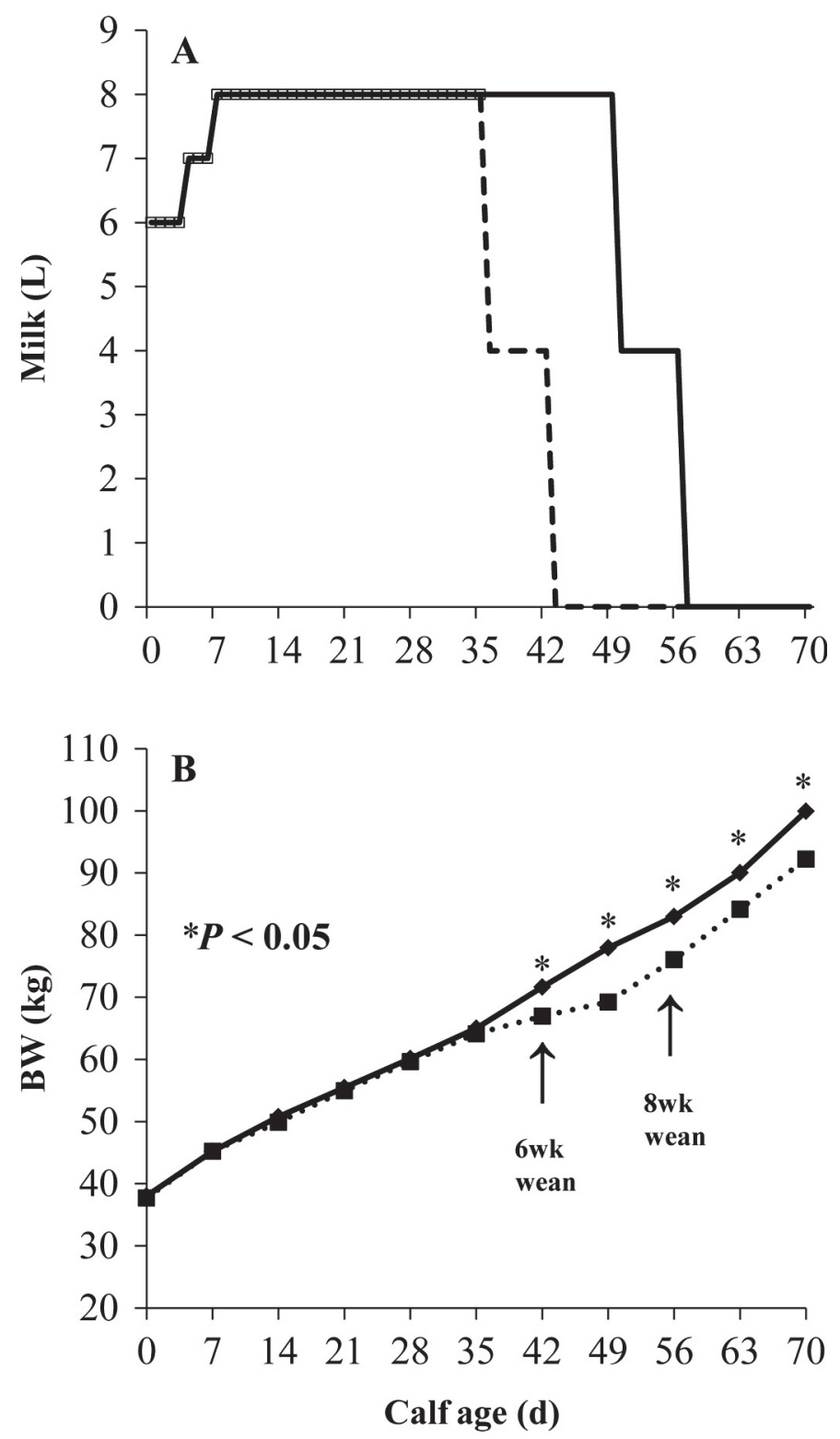

Figure 1. Experimental milk feeding regimen (A) and weekly BW (B) from calves weaned at $6 \mathrm{wk}$ (dotted line) or $8 \mathrm{wk}$ (solid line) for the first $10 \mathrm{wk}$ of life. ${ }^{*}$ Weekly means between calves weaned at $6 \mathrm{wk}$ and calves weaned at $8 \mathrm{wk}$ are different $(P<0.05)$. 
particle size. The starch content in fecal samples was analyzed at Cumberland Valley Laboratories (Hagerstown, MD) using methods described by Hall (2009).

At $\mathrm{d} 7( \pm 1 \mathrm{~d})$ and every week thereafter to $\mathrm{d} 70$, blood was collected. All blood was collected via jugular venipuncture using 12-mL (serum samples) Vacutainers (Becton Dickinson, Franklin Lakes, NJ) 3 h after morning feeding of starter $(1100 \mathrm{~h})$. After collection, blood in the serum Vacutainer tube sat at room temperature for $30 \mathrm{~min}$ before centrifugation at 3,000 $\times g$ for $15 \mathrm{~min}$ at room temperature. Serum was separated and stored at $-20^{\circ} \mathrm{C}$ until analysis for BHBA using spectrophotometry as described by Williamson et al. (1962). For the purpose of this experiment, results from d 35, 49, and 63 are reported.

\section{Behavioral Data Collection}

Behavior of all calves was observed $3 \mathrm{~d} /$ wk (Monday, Wednesday, and Friday) between 1500 and $1600 \mathrm{~h}$ from d 35 to 63 , during the period from 2 wk before weaning to 2 wk after weaning to maximize the distribution of measurements. The 1-h observation period per day was chosen based on work of Montoro et al. (2013), and the timing of the observation period $(-1.5$ to $-0.5 \mathrm{~h}$ before the afternoon milk delivery) was based on Miller-Cushon et al. (2013), who demonstrated very little milk feeding activity during those times of the day; we hypothesized that calves would show greater rumination, solid feed consumption, and other oral behaviors during that time period. A single researcher performed all observations to reduce variation. Every minute, the posture of the calf (standing or lying) and any other behaviors (ruminating, eating straw, eating starter, drinking water, playing, grooming, oral behavior, vocalizing, or being idle) were recorded. Ruminating was defined as the calf chewing when it had not ingested any feed or bedding in the previous 2 min. Eating starter or straw was defined as the calf lowering its head into the bucket and visibly chewing the feed. Oral behavior was defined as any non-nutritive sucking or licking.

\section{Treatment of Disease and Dehorning}

Treatment of disease followed standard operating procedures on the farm. Neonatal calf diarrhea was treated with a 1-mL subcutaneous injection of meloxicam solution (Metacam; Boehringer Ingelheim, Burlington, ON, Canada), and oral electrolyte therapy (Calf Lyte II; Vetoquinol, Lavaltrie, QC, Canada) was provided as required until scouring subsided. Respiratory disease was treated with florfenicol solution (NuFlor; Merck Animal Health) as directed on the bottle. All administered medications were recorded, along with any other pertinent information, such as indicators of disease (e.g., temperature, diarrhea, bloating, dehydration).

Calves were disbudded at $21 \mathrm{~d}( \pm 3 \mathrm{~d})$ using an electric cauterizer (Rhinehart X30; Rhinehart, Spencerville, IN). Each calf was given a 1-mL subcutaneous injection of meloxicam solution (Metacam) 30 min before cauterizing. A standard cornual nerve block procedure was used to minimize pain, in which $5 \mathrm{~mL}$ of lidocaine solution (Lido-2; Rafter 8, Calgary, AB, Canada) per horn was injected 20 min before cauterizing.

\section{Statistical Analysis}

Body weight, feed intake, rumen SCFA, blood BHBA, and fecal starch data were summarized and analyzed as one measurement per week, whereas all intake data were summarized for each week of the experiment. A preliminary analysis found no effect of week of entry into the study on treatment. The data were organized for each calf for each week of life, and for each week relative to weaning (WRW; $-3,-2$, step-down, weaning, +2), with the week of step-down beginning the day the calves were stepped down from 4 to $2 \mathrm{~L}$ twice daily (d 35 and 49 for $6 \mathrm{WW}$ and $8 \mathrm{WW}$ calves, respectively), and the week of weaning beginning the day calves received no milk (d 42 and 56 for $6 \mathrm{WW}$ and $8 \mathrm{WW}$ calves, respectively). To examine the effect of treatment, data were analyzed using the MIXED procedure of the statistical analysis system (SAS Institute, 2004), treating WRW as a repeated measure. The model included the fixed effects of WRW, treatment, week $\times$ WRW interaction, and the random effect of calf within treatment. Compound symmetry was selected as the variance-covariance matrix structure based on best fit according to Schwarz's Bayesian information criterion. Behavior data were summarized for each calf as the total time (min per hour of observation) devoted to each monitored behavior per day. These data were then summarized for each calf for each WRW $(-3,-2$, step-down, weaning, +2 ). Before analyses, all data were screened for normality using the UNIVARIATE procedure of SAS. Data on time spent ruminating, eating forage, eating starter, drinking water, playing, engaging in oral behavior, and vocalizing were right skewed. Thus, these behavioral data were transformed by taking the natural logarithm of each data point +1 . To examine the effect of treatment, these data were analyzed using the same MIXED procedure in SAS, treating WRW as a repeated measure. For all contrasts, a Tukey test was used to correct for multiple comparisons and all values reported are least squares means. When age at weaning $\times$ WRW interaction was detected, a Tukey test was used to correct for multiple comparisons between treatments by each WRW using the PDIFF statement 
in SAS. All values are reported as least squares means. Transformed data are shown in the results as backtransformed means. Significance was declared at $P \leq$ 0.05 and trends reported if $0.05<P \leq 0.10$.

\section{RESULTS}

\section{Intake, Growth, and BHBA Results}

Minimal orts were recorded in milk intake and we detected no differences between treatments, and thus results are not presented. During the week of stepdown, 6WW calves consumed approximately one-third of the amount of starter consumed by $8 \mathrm{WW}$ calves (Table 1). Although the $6 \mathrm{WW}$ calves had a lower starter intake, it rapidly increased (by 523\%) at weaning (Table 1), whereas $8 \mathrm{WW}$ calves had a $117 \%$ increase during the week of weaning. The most rapid increase of starter intake occurred during the week of weaning for both treatment groups (Figure 2); $6 \mathrm{WW}$ calves increased their starter intake by $240 \%$, whereas $8 \mathrm{WW}$ calves increased starter intake by $116 \%$. Water intake was similar to starter intake (Table 1), as the correlation coefficient between starter and water intake for both treatment groups was high $(\mathrm{r}=0.95 ; P<0.05)$ throughout the trial. Difference in straw intake between the treatment groups was most apparent in the week after the week of weaning (wk +2 in Table 1), with $8 \mathrm{WW}$ calves consuming $155 \%$ more than the amount consumed by $6 \mathrm{WW}$ calves (Table 1 ). However, overall starter intakes were not different during the last week of the experiment (63-70 d of life) in $6 \mathrm{WW}(3,260 \pm$ $196 \mathrm{~g})$ and $8 \mathrm{WW}(3,219 \pm 202 \mathrm{~g})$ calves.

Growth of $6 \mathrm{WW}$ calves reached a plateau at 0.35 $\mathrm{kg} / \mathrm{d}$ during the week of step-down, marking a $44 \%$ decrease from the prior week, and remained at $0.35 \mathrm{~kg} / \mathrm{d}$ during the week of weaning, before increasing again (Table 1; Figure 1B). For $8 \mathrm{WW}$ calves, the growth plateau was much less pronounced during the week of step-down, with only a $12 \%$ reduction from the week prior (0.90 to $0.79 \mathrm{~kg} / \mathrm{d}$ ), and lasting only $1 \mathrm{wk}$ (Table 1 ). During the week of step-down, $6 \mathrm{WW}$ calves had an ADG less than half that of $8 \mathrm{WW}$ calves (Table 1 ). This difference was more evident in the week of weaning, when the $8 \mathrm{WW}$ calves had an ADG 3 times higher than the $6 \mathrm{WW}$ calves (Table 1). The initial difference in BW between calves weaned at different ages began on d 36 and continued until d 70 (Figure 1). On d 70 of the study, $8 \mathrm{WW}$ calves weighed $99.9 \mathrm{~kg}, 9.8 \%$ more than $6 \mathrm{WW}$ calves $(91.0 \mathrm{~kg})$. The observed growth advantage was sustained in $8 \mathrm{WW}$ calves compared with $6 \mathrm{WW}$ calves at $\mathrm{d} 90(127 \pm 2.1$ vs $118 \pm 2.2)$ and $\mathrm{d} 150(194$ \pm 5.2 vs $183 \pm 4.8 ; P=0.09)$.

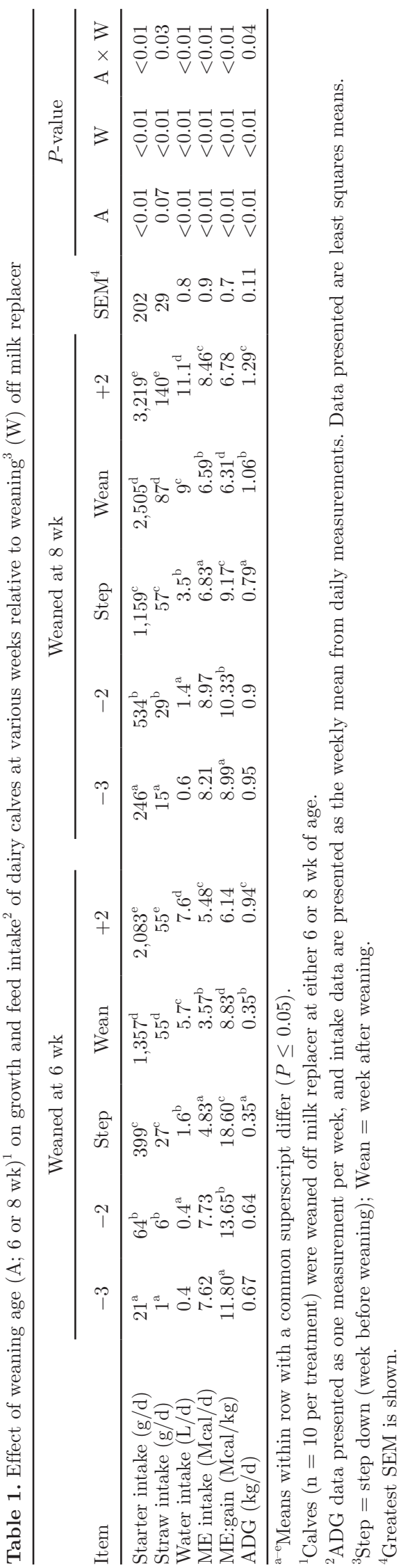

Journal of Dairy Science Vol. 98 No. 9, 2015 

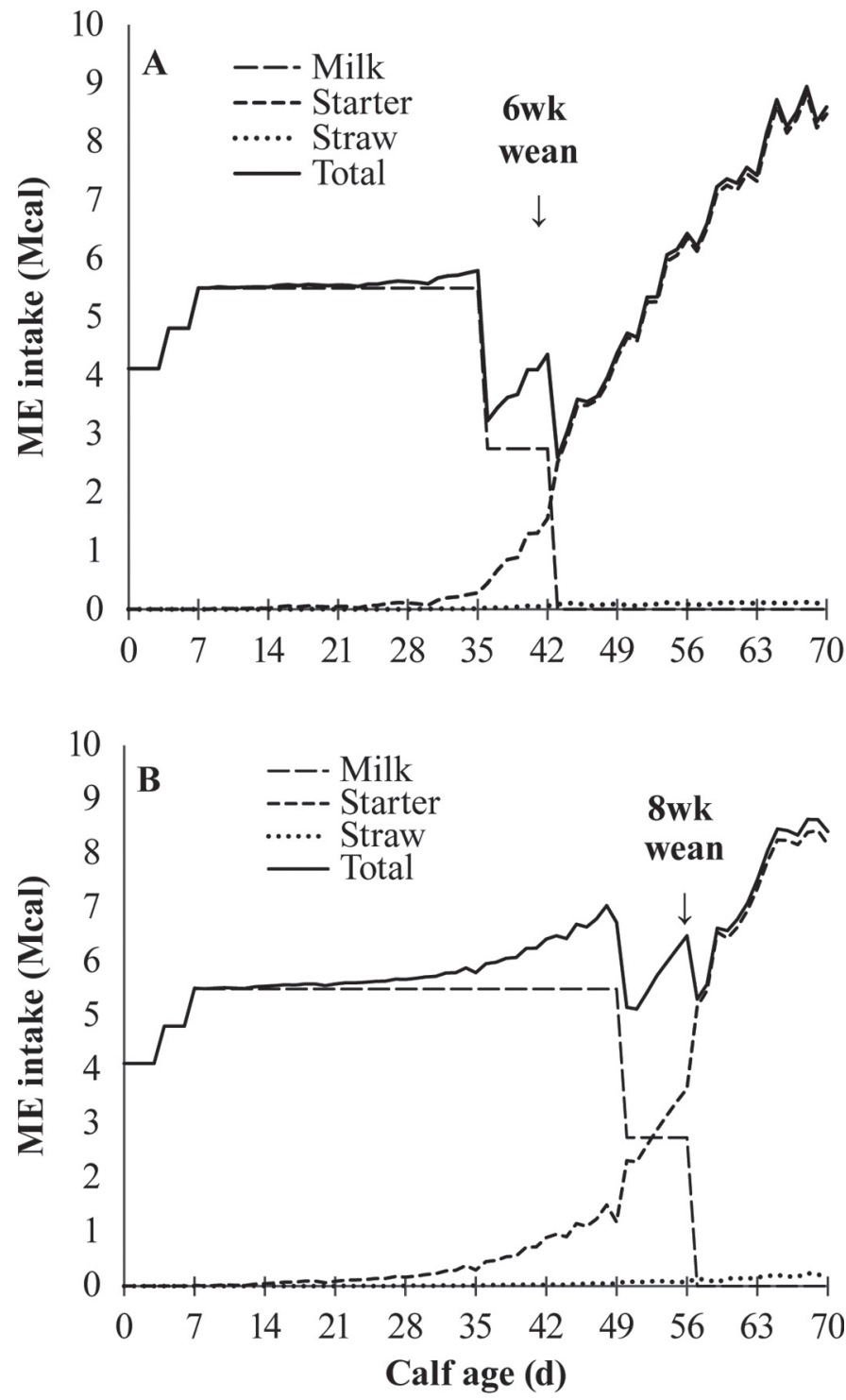

Figure 2. Mean estimated daily ME intake from milk, starter, and straw from 0 to $70 \mathrm{~d}$ of life from calves weaned at $6 \mathrm{wk}(\mathrm{A})$ and $8 \mathrm{wk}$ (B) of age.

When taking the weekly average, $6 \mathrm{WW}$ calves experienced a $44 \%$ reduction in ME consumed as the step-down occurred, whereas $8 \mathrm{WW}$ calves experienced only a $21 \%$ decrease. This reduction occurred again at weaning, with $6 \mathrm{WW}$ calves reducing ME consumption by $36 \%$ and $8 \mathrm{WW}$ calves reducing by $14 \%$. The ratio of ME:gain was also reduced for both groups in the week of weaning (Table 1). However, the reduction in ME:gain and feed:gain was greater in $6 \mathrm{WW}$ calves $(55$ and $65 \%$, respectively) compared with $8 \mathrm{WW}$ calves (14 and $20 \%$, respectively) in the week of weaning (Table $1)$.

\section{Gastrointestinal Observations}

Starter intake, rumen fluid $\mathrm{pH}$, SCFA concentration, blood BHBA concentration, and fecal starch percentage in $6 \mathrm{WW}$ and $8 \mathrm{WW}$ calves on $\mathrm{d} 35,49$, and 63 are shown in Figure 3. Weaning increased solid feed intake, which coincided with decreased ruminal $\mathrm{pH}$ and increased ruminal total SCFA and butyrate for both groups (Figure 3B, C, D). On d 49 of life, we observed a trend $(P=0.10)$ for ruminal SCFA concentration to be higher in the 6 -wk-old calves (1 wk after weaning) compared with 8 -wk-old calves (1 wk before weaning). From d 35 to 49 of life, ruminal SCFA and butyrate of $8 \mathrm{WW}$ calves increased by 80 and $140 \%$ in calves, respectively, but there were no differences between wk 7 and 9 in both treatment groups. The blood BHBA results were similar to those for starter intake and ruminal SCFA concentration (Figure 3E). In contrast to ruminal SCFA concentrations, blood BHBA values differed between $6 \mathrm{WW}$ and $8 \mathrm{WW}$ calves on d 49 . An increase in the percentage of fecal starch was evident in both treatment groups after weaning, but the increase was more pronounced in $6 \mathrm{WW}$ calves compared with $8 \mathrm{WW}$ calves (Figure 3D). Fecal starch increased by $360 \%$ in $6 \mathrm{WW}$ calves from d 35 to 49 compared with $8 \mathrm{WW}$ calves, in which fecal starch increased by $200 \%$ from d 49 to 63 (Figure 3D). Furthermore, from d 49 to $63,6 \mathrm{WW}$ calves showed an adaptive response and reduced the percentage of fecal starch.

\section{Behavioral Observations}

The effect of weaning age on calf behavior is shown in Table 2. The $6 \mathrm{WW}$ calves spent $36 \%$ less time lying down during the week of step-down compared with $8 \mathrm{WW}$ calves. However, $6 \mathrm{WW}$ calves spent $41 \%$ more time lying down in the week of weaning. The largest difference in rumination time was observed in the week before step-down, with $6 \mathrm{WW}$ calves only ruminating for $26 \%$ the amount of time as $8 \mathrm{WW}$ calves. The $8 \mathrm{WW}$ calves spent $271 \%$ more time consuming straw in the week of weaning and $480 \%$ more time consuming straw in the week after weaning. Across the step-down period, time spent eating starter tended to increase, as did time spent drinking water. Across weeks, time spent eating starter and drinking water was greater for $8 \mathrm{WW}$ calves. The $6 \mathrm{WW}$ calves spent $207 \%$ more time playing during the week before step-down. Time spent grooming tended to decrease across the step-down period and was lower across weeks for $8 \mathrm{WW}$ calves. Time engaged in oral behavior tended to be $138 \%$ greater in $6 \mathrm{WW}$ calves during the week before step-down, whereas it tended to be $171 \%$ greater in $8 \mathrm{WW}$ calves during the week after 

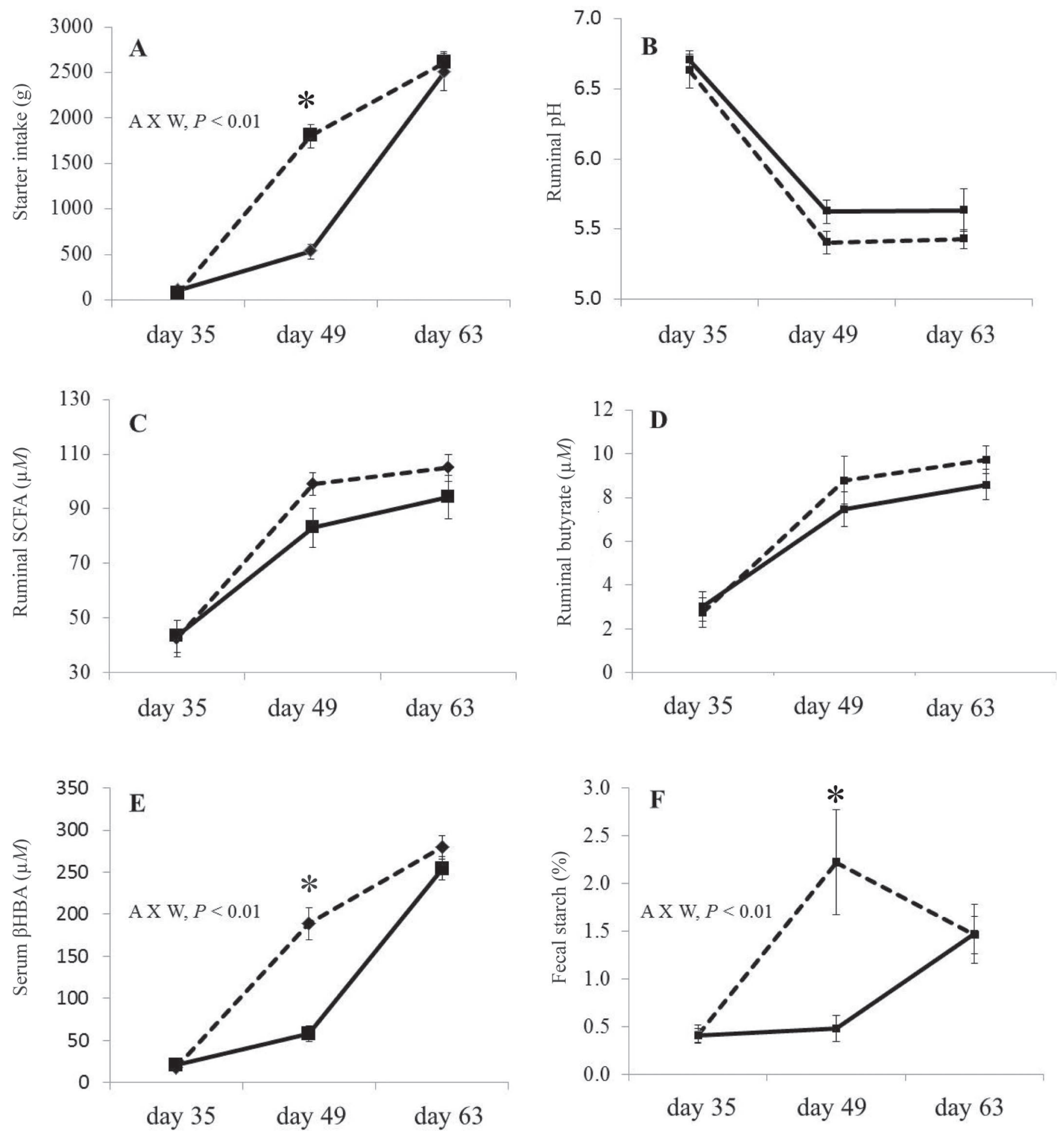

Figure 3. Summary of mean starter intake (A), ruminal pH (B), total ruminal short-chain FA (C), ruminal butyrate (D), blood $\beta$-hydroxybutyrate (E), and fecal starch \% (F) from calves weaned at 6 wk (dotted line) or 8 wk (solid line) on d 35, 49, and 56 of life. ${ }^{*}$ Weekly means between 6 -wk calves and 8 -wk calves are different $(P<0.05)$. Age of weaning and week of life interactions $(\mathrm{A} \times \mathrm{W})$ that are different are indicated on graphs. 
weaning. The $6 \mathrm{WW}$ calves vocalized more across the observation period.

\section{DISCUSSION}

Early weaning has traditionally been recommended in the dairy industry to accelerate rumen development, ultimately reducing the cost to feed a calf (Kertz et al., 1979; Quigley and Caldwell, 1991). However, over the past decade, there has been mounting evidence to support the use of elevated planes of nutrition to improve growth and animal welfare during the preweaning phase of development (Khan et al., 2011) and potentially milk production later in life (Soberon and VanAmburgh, 2013). Weaning strategy becomes critical when larger volumes of milk are fed, because solid feed intake establishes ruminal fermentation, thereby triggering physical and metabolic development of the calf (Baldwin et al., 2004). To date, several weaning strategies have been developed, including concentrate intake dependence (Leaver and Yarrow, 1972; Greenwood et al., 1997; Roth et al., 2009; de Passillé and Rushen, 2012), step-down milk reduction (Khan et al., 2007), and lengthening the duration of the weaning period (Terré et al., 2006; Hill et al., 2012). However, there has been a lack of emphasis on determining the effect of weaning age on intake, digestive tract development, and behavior when calves are fed larger quantities of milk. It is also unknown if a reduction in ADG during the transition of weaning have any long-term effect on physiology, behavior or lifetime production.

The concept of later weaning to enhance feed intake and maintain growth rates during weaning has been established in piglets and beef calves, which are fed milk preweaning ad libitum. However, this concept has not been established in dairy calves. For example, piglets weaned at $21 \mathrm{~d}$ compared with $12 \mathrm{~d}$ had higher ADG at weaning, as well as improved weights later in life at finishing (Main et al., 2004). Similarly, the growth advantage immediately after weaning was sustained in this experiment until months after weaning. The sustained growth increase in the current experiment is unique, as it moves beyond previous studies relating to superior growth from preweaning schemes, which typically did not demonstrate longer-term growth advantages for the months after weaning (Shamay et al., 2005; Davis-Rincker et al., 2011).

In the current study, all calves consumed minimal starter during the first weeks of the life and began to increase starter consumption at approximately $4 \mathrm{wk}$. This is in agreement with previous reports that suggest the initiation of solid feed intake, as well as subsequent ruminal fermentation, assists with rumen development and is noticeable by 4 wk of age (Warner et al., 1956;

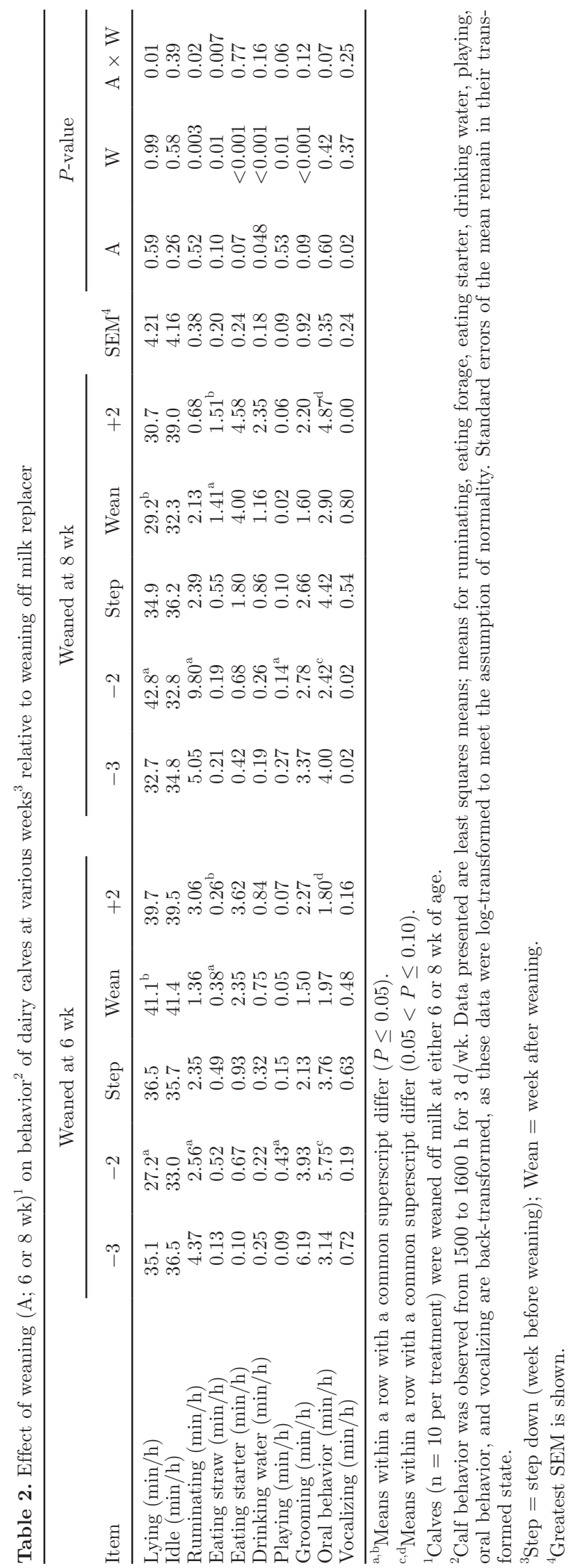


Sander et al., 1959; Tamate et al., 1961). A substantial increase in starter consumption did not occur until step-down of milk, which is consistent with findings from other weaning strategies (Leaver and Yarrow, 1972; de Passillé and Rushen, 2012; Hill et al., 2012). The decrease in ME intake at step-down and weaning resulted in an ADG decrease, which is commonly seen in literature pertaining to calves being fed higher planes of nutrition in automated systems (Jasper and Weary 2002; Borderas et al., 2009, Sweeney et al., 2010). The reduction in ADG was far more pronounced for $6 \mathrm{WW}$ calves compared with $8 \mathrm{WW}$ calves in this study. Our results were also in line with de Passillé and Rushen (2012), who demonstrated that calves fed $12 \mathrm{~L} / \mathrm{d}$ milk via an automated feeding system and weaned later (12 vs. $8 \mathrm{wk}$ ) had higher intakes of starter and digestible energy, as well as greater weight gains during the weaning period ( 0.5 vs $1.0 \mathrm{~kg} / \mathrm{d}$ ). Future studies should quantify the proportions of ADG from increased intake and gut fill, gut growth, and body growth.

An alternative to weaning by age, which is common in our industry, is the traditional concentrate- or starter-dependent weaning strategy. Optimal preweaning starter intake before step down $(>0.5 \mathrm{~kg} / \mathrm{d})$ is essential for postweaning intake and gain and is influenced by the nutrient content of the milk replacer and calf starter (Stamey et al., 2012; Kertz and Loften, 2013). Greenwood et al. (1997) demonstrated that calves fed low planes of nutrition could be successfully weaned when starter intake reaches $1 \%$ of $\mathrm{BW}$. It was also determined that postweaning growth did not differ between calves that were weaned when starter intake reached 1.5 and $2.0 \%$ of BW (Greenwood et al., 1997). In the current study, weaning was based on age, and reduction of milk resulted in an increase in starter intake. This finding opposes the concentrate-dependent method, in which the level of starter intake prompts the milk reduction. In the current trial, calves weighed 66.5 $\mathrm{kg}$ when weaned at $6 \mathrm{wk}$ and $83.5 \mathrm{~kg}$ when weaned at $8 \mathrm{wk}$, thereby requiring starter intakes of 0.67 and 0.84 $\mathrm{kg} / \mathrm{d}$, respectively, to reach $1 \%$ of $\mathrm{BW}$. This target was easily achieved for $8 \mathrm{WW}$ calves, which consumed $1.38 \%$ of BW the week before weaning. However, this target was not met for $6 \mathrm{WW}$ calves, which consumed only $0.6 \%$ of BW the week before weaning. Ultimately, this finding indicates that when feeding $1.2 \mathrm{~kg} / \mathrm{d}$ of $\mathrm{MR}$, weaning at $6 \mathrm{wk}$ is too early when calves are weaned according to the concentrate intake as a percentage of BW (Greenwood et al., 1997). Calves weaned at $6 \mathrm{wk}$ could not achieve optimal starter intake during stepdown and weaning, which had a longstanding effect on gastrointestinal development and growth. However, calves weaned at 8 wk had higher starter intake preweaning and were more able to maintain adequate $\mathrm{ME}$ intake postweaning, possibly due to gastrointestinal and metabolic development from higher levels of solid feed intake preweaning.

To assess gastrointestinal development in this study, ruminal concentrations of SCFA, blood BHBA, and fecal starch percentage were measured. Ruminal SCFA concentrations were used as a marker of microbial fermentation in the rumen. On d 35 of life, before stepdown weaning, ruminal fluid concentration was $<50$ $\mathrm{m} M$, which agrees with some previous reports (Anderson, 1981; Lesmeister et al., 2004; Laarman et al., 2012) but contrasts other reports that showed higher concentrations during the first month of life (Rey et al., 2012). Interestingly, the SCFA and butyrate concentrations of calves the week before weaning were higher in $8 \mathrm{WW}$ calves, indicating greater microbial fermentation within the rumen before weaning. The end-products of microbial fermentation, namely butyrate and propionate, have been shown to induce ruminal growth (Baldwin et al., 2004). The greater concentration of microbial end-products available to trigger ruminal development may be one contributing factor to improving the transition to weaning. The age- and diet-dependent factors of microbial and epithelial functional development during weaning in the rumen require further exploration.

Weaning marks the shift away from the majority of energy from intestinal absorption of nutrients to energy being derived from ruminal microbial fermentation and the production of SCFA being absorbed and metabolized by the rumen epithelium (Baldwin et al., 2004). The major metabolic pathway of SCFA metabolism in the rumen epithelium is ketogenesis (Leighton et al., 1983). Blood BHBA was similar for both treatment groups up to $\mathrm{d} 35(<100 \mu M)$ while they were consuming the same minimal amounts of starter. However, blood BHBA of $6 \mathrm{WW}$ calves increased significantly at step-down, in association with starter intake. The BHBA results agree with those in some studies (Khan et al., 2011), ranging from 0 to $400 \mu M$, which is lower than reported by others (Quigley and Caldwell, 1991). This sharp increase in blood BHBA is similar to results in lambs weaned during wk 7 of life, where BHBA increased 6-fold between 42 and $56 \mathrm{~d}$ of age (Baldwin and Jesse, 1992). Although morphological development is clearly affected by diet, the ketogenic capacity of the rumen epithelium has been shown to increase with age in lambs (Lane et al., 2002). Similarly, Bush (1988) found that calves were only at $40 \%$ the ketogenic rate of a mature ruminant at $30 \mathrm{~d}$ of age, despite being weaned at $28 \mathrm{~d}$. By $60 \mathrm{~d}$ of age, calves were producing ketones at rates similar to that of a mature ruminant, which also agrees with early work by Warner et al. (1956) and Tamate et al. (1961). This suggests that certain steps in rumen maturity do not occur before 8 wk of age. It should be 
noted that blood ketones could also increase because of fat mobilization, especially during times when energy requirements for maintenance are not being consumed (McGarry et al., 1973; Pan et al., 2000). Thus, even though there is no evidence for this in calves, some of the increase in blood BHBA levels during weaning may be attributable to an increase in fat mobilization and not all due to the amount of starter consumed.

In addition to ruminal metrics, the total digestive tract starch digestibility was assessed by fecal starch quantification (Fredin et al., 2014). It has been well established in lactating dairy cows that a decrease in fecal starch is associated with increased feed efficiency and milk production (Firkins et al., 2001); however, fecal starch has not been used for or validated as a marker of weaning success in calves. In the current experiment, fecal starch percentages were lower in the preweaning phase (d 35 of life) compared with that reported in lactating dairy cows (Fredin et al., 2014). The $6 \mathrm{WW}$ calves displayed the highest and most variable fecal starch levels, exceeding that of $8 \mathrm{WW}$ calves 1 wk after weaning. The larger variation of $6 \mathrm{WW}$ calves postweaning may reflect the irregularities of solid feed intake, behavior, passage rate, and digestive tract development during weaning. There is a need for more research on using fecal starch as a measure of weaning success in dairy calves based on these results. Although many factors need to be considered, the increase in fecal starch provides another indication that the total digestive tract is not optimally established for carbohydrate digestion at 6 wk compared with 8 wk. In spite of these results, starch did not reach levels associated with inflammation of the gut $(>5 \%)$ as characterized in lactating dairy cattle ( $\mathrm{Li}$ et al., 2010). The collective results imply that calves weaned at 8 wk are better able to handle the dramatic increase in SCFA production of ruminal fermentation, are better equipped to synthesize and utilize BHBA postweaning, and display greater postweaning total starch digestibility. These findings warrant further investigation to determine the interface between total gastrointestinal tract microbial fermentation and host digestive tract development during weaning.

Several behavioral indicators coincided with improved intake. During the week of weaning, $8 \mathrm{WW}$ calves spent 4 times the amount of time ruminating than $6 \mathrm{WW}$ calves. The $8 \mathrm{WW}$ calves spent more time eating straw during the week of weaning and tended to spend more time eating starter during the week before step down and the week after weaning. These results are consistent with the greater amount of starter and straw eaten by $8 \mathrm{WW}$ calves and align with Worobec et al. (1999), who found that greater age at weaning increased time spent eating solid feed in piglets. As expected, time spent eating starter and drinking water increased over time in both treatments, which is attributable to the increased consumption of water and starter as the calves grew and transitioned to solid feed.

The effect of weaning age on distress during weaning was also observed throughout this study. Stress at weaning can be caused by a variety of factors, including a change in diet or a change in the social and physical environment (Weary et al., 2008). Calves in the current study remained isolated in their original pen until the end of the experiment at 10 wk of age; therefore, stress would primarily result from the significant change in diet. Vocalizations at weaning can be attributed to hunger, as shown by Thomas et al. (2001), who measured vocalizations in calves deprived of milk. It is thought that this behavior is expressed by the calf to signal to its caregivers that it is in need, in this case, of nutritional sustenance (Weary et al., 2008). Piglets weaned earlier call more in the $4 \mathrm{~d}$ after weaning, suggesting that changes in vocalizations are the most distinct immediately after step-down or weaning (Weary and Fraser, 1997). Similarly, 6WW calves in the current study vocalized more than $8 \mathrm{WW}$ calves across the entire observation period. The increased vocalizations may be caused by the hunger associated with the lack of ME intake when weaning is performed too early, indicating malnutrition, significant health and welfare issues (Thomas et al., 2001; Dawkins, 2008; de Paula Vieira et al., 2008), and decreased immune function (Williams et al., 1981; Pollock et al., 1993; Nonnecke et al., 2003).

Oral behavior and non-nutritive sucking have been associated with lower milk intake (Jung and Lidfords, 2001). During the week before step-down, $6 \mathrm{WW}$ calves performed 2.4 times more oral behaviors than $8 \mathrm{WW}$ calves, suggesting increased hunger. This finding further supports work by de Passillé et al. (2011), who suggested that cross-sucking is not always related to milk intake or weaning but may be more a characteristic of the individual calf.

\section{CONCLUSIONS}

The results of this study suggest that calves fed a higher quantity of milk preweaning $(1.2 \mathrm{~kg} / \mathrm{d}$ of $\mathrm{MR})$ have more nutrient intake, higher growth rates, more gastrointestinal development at weaning, and fewer behavioral signs of weaning distress when weaned at $8 \mathrm{wk}$ compared with 6 wk of age. In summary, calves weaned at $8 \mathrm{wk}$ were better able to cope with the transition from milk to solid feed compared with calves weaned at $6 \mathrm{wk}$, as they had greater solid feed intakes before, during, and after weaning. Further research exploring the specific biological mechanisms that are being 
triggered by age in combination with diet would be beneficial when developing new feeding strategies to optimize dairy calf growth and development pre- and postweaning.

\section{ACKNOWLEDGMENTS}

The authors gratefully acknowledge the support of Christa Eckert and all staff at Eckerlea Acres Ltd. (Seaforth, ON, Canada). We are thankful for the financial support and donations provided by Nutreco Canada Inc. (Guelph, ON, Canada), Grober Nutrition (Cambridge, ON, Canada), and Nieuwland Feed and Supply Ltd. (Drayton, ON, Canada). We also appreciate the technical advice offered by John Metcalf, John Doelman, and Douglas Waterman (Nutreco Canada Inc.) and technical assistance provided by Vivienne Beilman, Stephen Elgersma, and Julia Romagnoli.

\section{REFERENCES}

Anderson, B. C. 1981. Patterns of shedding of cryptosporidial oocysts in Idaho calves. J. Am. Vet. Med. Assoc. 178:982-984.

Appleby, M., D. Weary, and B. Chua. 2001. Performance and feeding behaviour of calves on ad libitum milk from artificial teats. Appl. Anim. Behav. Sci. 74:191-201.

Baldwin, R. L., VI, and B. W. Jesse. 1992. Developmental changes in glucose and butyrate metabolism by isolated sheep rumen epithelium cells. J. Nutr. 122:1149-1153.

Baldwin, R. L., VI, K. R. McLeod, J. L. Klotz, and R. N. Heitmann. 2004. Rumen development, intestinal growth and hepatic metabolism in the pre- and postweaning ruminant. J. Dairy Sci. 87(E. Suppl.):E55-E65.

Benschop, D. L., and J. P. Cant. 2009. Developmental changes in clearance of intravenous doses of glucose, acetate and $\beta$-hydroxybutyrate from plasma of calves. Livest. Sci. 122:177-185.

Bielmann, V., J. Gillan, N. R. Perkins, A. L. Skidmore, S. Godden, and K. E. Leslie. 2010. An evaluation of Brix refractometry instruments for measurement of colostrum quality in dairy cattle. J. Dairy Sci. 93:3713-3721.

Borderas, T. F., A. M. B. de Passillé, and J. Rushen. 2009. Feeding behavior of calves fed small or large amounts of milk. J. Dairy Sci. 92:2843-2852.

Bush, R. S. 1988. Effect of age and diet on in vitro metabolism in rumen epithelium from Holstein calves. Can. J. Anim. Sci. 68:12451251.

Canadian Council of Animal Care (CCAC). 2009. The Care and Use of Farm Animals in Research, Teaching and Testing. CCAC, Ottawa, ON, Canada.

Davis Rincker, L. E., M. J. VandeHaar, C. A. Wolf, J. S. Liesman, L. T. Chapin, and M. S. Weber Nielsen. 2011. Effect of intensified feeding of heifer calves on growth, pubertal age, calving age, milk yield, and economics. J. Dairy Sci. 94:3554-3567.

Dawkins, M. S. 2008. The science of animal suffering. Ethology 114:937-945

de Passillé, A. M., F. Borderas, and J. Rushen. 2011. Cross-sucking by dairy calves may become a habit or reflect characteristics of individual calves more than milk allowance or weaning. Appl. Anim. Behav. Sci. 133:137-143.

de Passillé, A. M., and J. Rushen. 2012. Adjusting the weaning age of calves fed by automated feeders according to individual intakes of solid feed. J. Dairy Sci. 95:5292-5298. de Passillé, A. M. B. P., G. Marnet, H. Lapierre, and J. Rushen. 2008. Effects of twice-daily nursing on milk ejection and milk yield during nursing and milking in dairy cows. J. Dairy Sci. 91:1416-1422.

de Paula Vieira, A., V. Guesdon, A. M. de Passille, M. A. G. von Keyserlingk, and D. M. Weary. 2008. Behavioural indicators of hunger in dairy calves. Appl. Anim. Behav. Sci. 109:180-189.

Firkins, J. L., M. L. Eastridge, N. R. St-Pierre, and S. M. Noftsger. 2001. Effects of grain variability and processing on starch utilization by lactation dairy cattle. J. Anim. Sci. 79:218-238.

Fredin, S. M., L. F. Ferraretto, M. S. Akins, P. C. Hoffman, and R. D. Shaver. 2014. Fecal starch as an indicator of total-tract starch digestibility by lactating dairy cows. J. Dairy Sci. 97:1862-1871.

Greenwood, R. H., J. L. Morrill, and E. C. Titgemeyer. 1997. Using dry feed intake as a percentage of initial body weight as a weaning criterion. J. Dairy Sci. 80:2542-2546.

Hall, M. B. 2009. Analysis of starch, including maltooligosaccharides in animal feeds: A comparison of methods and a recommended method for AOAC collaborative study. J. AOAC Int. 92:42-49.

Hill, T. M., H. G. Bateman II, J. M. Aldrich, and R. L. Schlotterbeck. 2012. Methods of reducing milk replacer to prepare dairy calves for weaning when large amounts of milk replacer have been fed. Prof. Anim. Sci. 28:332-337.

Jasper, J., and D. M. Weary. 2002. Effects of ad libitum milk intake on dairy calves. J. Dairy Sci. 85:3054-3058.

Jung, J., and L. Lidfords. 2001. Effects of amount of milk, milk flow, and access to a rubber teat on cross-sucking and non-nutritive sucking in dairy calves. Appl. Anim. Behav. Sci. 72:201-213.

Kertz, A. F., and J. R. Loften. 2013. Review: A historical perspective of specific milk-replacer feeding program in the United States and effects on eventual performance of Holstein dairy calves. Prof. Anim. Sci. 29:321-332.

Kertz, A. F., L. R. Prewitt, and J. P. Everett Jr. 1979. An early weaning calf program: Summarization and review. J. Dairy Sci. 62:1835-1843.

Khan, M. A., H. J. Lee, W. S. Lee, H. S. Kim, S. B. Kim, K. S. Ki, J. K. Ha, H. G. Lee, and Y. J. Choi. 2007. Pre- and postweaning performance of Holstein female calves fed milk through step-down and conventional methods. J. Dairy Sci. 90:876-885.

Khan, M. A., D. M. Weary, and M. A. G. von Keyserlingk. 2011. Invited Review: Effects of milk ration on solid feed intake, weaning, and performance in dairy heifers. J. Dairy Sci. 94:1071-1081.

Laarman, A. H., A. Ruiz-Sanchez, T. Sugino, L. L. Guan, and M. Oba. 2012. Effects of feeding a calf starter on molecular adaptations in the ruminal epithelium and liver of Holstein dairy calves. J. Dairy Sci. 95:2585-2594.

Lane, M. A., R. L. Baldwin VI, and B. W. Jesse. 2002. Developmental changes in ketogenic enzyme gene expression during sheep rumen development. J. Anim. Sci. 80:1538-1544.

Leaver, J. D., and N. H. Yarrow. 1972. Rearing of dairy cattle. Weaning calves according to their concentrate intake. Anim. Prod. 14:161-165.

Leighton, B., A. R. Nicholas, and C. I. Pogson. 1983. The pathway of ketogenesis in rumen epithelium of the sheep. Biochem. J. 216:769-772.

Lesmeister, K. E., A. J. Heinrichs, and M. T. Gabler. 2004. Effects of supplemental yeast (Saccharomyces cerevisiae) culture on rumen development, growth characteristics, and blood parameters in neonatal dairy calves. J. Dairy Sci. 87:1832-1839.

Li, S., E. Khafipour, D. O. Krause, J. C. Rodriguez-Lecompte, and J. C. Plaizier. 2010. Lipopolysaccharide endotoxin (LPS) in the feces of lactating dairy cows. Can. J. Anim. Sci. 90:591-594.

Main, R. G., S. S. Dritz, M. D. Tokach, R. D. Goodband, and J. L. Nelssen. 2004. Increasing weaning age improves pig performance in a multisite production system. J. Anim. Sci. 82:1499-1507.

McGarry, J. D., J. M. Meier, and D. W. Foster. 1973. The effects of starvation and refeeding on carbohydrate and lipid metabolism in vivo and in the perfused rat liver. J. Biol. Chem. 248:270-278.

Miller-Cushon, E. K., R. Bergeron, K. E. Leslie, and T. J. DeVries. 2013. Effect of milk feeding level on development of feeding behavior in dairy calves. J. Dairy Sci. 96:551-564. 
Montoro, C., E. K. Miller-Cushon, T. J. DeVries, and A. Bach. 2013. Effect of physical form of forage on performance, feeding behavior, and digestibility of Holstein calves. J. Dairy Sci. 96:1117-1124.

Mutsvangwa, T., J. P. Walton, J. C. Plaizier, T. F. Duffield, R. Bagg, P. Dick, G. Vessie, and B. W. McBride. 2002. Effects of monensin controlled-release capsule or premix on attenuation of subacute ruminal acidosis in dairy cows. J. Dairy Sci. 85:3454-3461.

Noller, C. H., I. A. Dickson, and D. L. Hill. 1962. Value of hay and rumen inoculation in an early-weaning system for dairy calves. J. Dairy Sci. 45:197-201.

Nonnecke, B. J., M. R. Foote, J. M. Smith, B. A. Pesch, and M E. Van Amburgh. 2003. Composition and functional capacity of blood mononuclear leukocyte populations from neonatal calves on standard and intensified milk replacer diets. J. Dairy Sci. 86:3592-3604.

Pan, J. W., D. L. Rothman, K. L. Behar, D. T. Stein, and H. P. Hetherington. 2000. Human brain $\beta$-hydroxybutyrate and lactate increase in fasting-induced ketosis. J. Cereb. Blood Flow Metab. $20: 1502-1507$

Pollock, J. M., T. G. Rowen, J. B. Dixon, S. D. Carter, D. Spiller, and H. Warenius. 1993. Alteration of cellular immune responses by nutrition and weaning in calves. Res. Vet. Sci. 55:298-305.

Quigley, J. D., and L. A. Caldwell. 1991. Changes in blood glucose, nonesterified fatty acids, and ketones in response to weaning and feeding intake in young calves. J. Dairy Sci. 74:250-257.

Reinhardt, V., and A. Reinhardt. 1981. Natural sucking performance and age at weaning in zebu cattle (Bos indicus). J. Agric. Sci 96:309-312.

Rey, M., F. Enjalbert, and V. Monteils. 2012. Establishment of ruminal enzyme activities and fermentation capacity in dairy calves from birth through weaning. J. Dairy Sci. 95:1500-1512.

Roth, B. A., N. M. Keil, L. Gygax, and E. Hillmann. 2009. Influence of weaning method on health status and rumen development in dairy calves. J. Dairy Sci. 92:645-656.

Sander, E. G., R. G. Warner, H. N. Harrison, and J. K. Loosli. 1959. The stimulatory effect of sodium butyrate and sodium propionate on the development of rumen mucosa in the young calf. J. Dairy Sci. 42:1600-1605.

SAS Institute. 2004. SAS/STAT Users Guide. Release 9.1. SAS Inst. Inc., Cary, NC.

Shamay, A., D. Werner, U. Moallem, H. Barash, and I. Bruckental. 2005. Effect of nursing management and skeletal size at weaning on puberty, skeletal growth rate, and milk production during first lactation of dairy heifers. J. Dairy Sci. 88:1460-1469.

Soberon, F., E. Raffrenato, R. W. Everett, and M. E. Van Amburgh. 2012. Preweaning milk replacer intake and effects on long-term productivity of dairy calves. J. Dairy Sci. 95:783-793.
Soberon, F., and M. E. VanAmburgh. 2013. Lactation Biology Symposium: The effect of nutrient intake from milk or milk replacer of preweaned dairy calves on lactation milk yield as adults: A metaanalysis of current data. J. Anim. Sci. 91:706-712.

Stamey, J. A., N. A. Janovick, A. F. Kertz, and J. K. Drackley. 2012. Influence of starter protein content on growth of dairy calvdes in an enhanced early nutrition program. J. Dairy Sci. 95:3327-3336.

Stanton, A. L., D. F. Kelton, S. J. LeBlanc, J. Wormuth, L. K. Fox and K. E. Leslie. 2013. Effects of tulathromycin on incidence of various diseases and growth of young heifers. J. Am. Vet. Med. Assoc. 243:267-276

Sweeney, B. C., J. Rushen, D. M. Weary, and A. M. de Passillé. 2010. Duration of weaning, starter intake, and weight gain of dairy calves fed large amounts of milk. J. Dairy Sci. 93:148-152.

Tamate, H., A. D. McGilliard, N. L. Jacobson, and R. Getty. 1961. Effect of various dietaries on the anatomical development of the stomach in the calf. J. Dairy Sci. 45:408-420.

Terré, M., A. Bach, and M. Devant. 2006. Performance and behavior of calves reared in groups or individually following and enhancedgrowth feeding program. J. Dairy Res. 73:480-486.

Thomas, T. J., D. M. Weary, and M. C. Appleby. 2001. Newborn and 5-week-old calves vocalize in response to milk deprivation. Appl. Anim. Behav. Sci. 74:165-173.

Trotz-Williams, L. A., B. D. Jarvie, A. S. Peregrine, T. F. Duffield, and K. E. Leslie. 2011. Efficacy of halofluginone lactate in prevention of cryptosporidiosis in dairy calves. Vet. Rec. 168:509.

Warner, R. G., W. P. Flatt, and J. K. Loosli. 1956. Dietary factors influencing the development of the ruminant stomach. J. Agric. Food Chem. 4:788-792.

Weary, D. M., and D. Fraser. 1997. Vocal response of piglets to weaning: Effect of piglet age. Appl. Anim. Behav. Sci. 54:153-160.

Weary, D. M., J. Jasper, and M. J. Hötzel. 2008. Understanding weaning distress. Appl. Anim. Behav. Sci. 110:24-41.

Williams, P. E. V., N. Day, A. M. Raven, and J. A. McLean. 1981. The effect of climatic housing and level of nutrition on the performance of dairy calves. Anim. Prod. 32:133-141.

Williamson, D. H., J. Mellanby, and H. A. Krebs. 1962. Enzymatic determination of $\mathrm{d}(-)-\beta$-hydroxybutyric acid and acetoacetic acid in blood. Biochem. J. 82:90-96.

Winter, K. A. 1985. Comparative performance and digestibility in dairy calves weaned at three, five, and seven weeks of age. Can. J. Anim. Sci. 65:445-450.

Worobec, E., I. Duncan, and T. Widoski. 1999. The effects of weaning at 7,14 and 28 days on piglet behaviour. Appl. Anim. Behav. Sci. 62:173-182. 